\title{
PROMOSI KESEHATAN DENGAN MEDIA AUDIOVISUAL DAN NON AUDIOVISUAL TERHADAP PERILAKU PENCEGAHAN STUNTING PADA REMAJA
}

\author{
Bela Novita Amaris Susanto1), Nofri Zayani'1), Selvy Afrioza1), Rd. Deden Gumilar Nugraha2) \\ 1)Program Studi Keperawatan, STIKes YATSI Tangerang, Banten, Indonesia \\ 2) Perwakilan BKKBN Provinsi Banten, Indonesia \\ Corresponding author : Bela Novita Amaris Susanto \\ E-mail : bnamaris@gmail.com
}

Diterima 05 Oktober 2021, Direvisi 19 Oktober 2021, Disetujui 19 Oktober 2021

\begin{abstract}
ABSTRAK
Kualitas suatu remaja merupakan salah satu faktor yang dapat menentukan angka kejadian stunting. Kurangnya pemberian informasi yang benar tentang memeperisapkan pencegahan stunting sejak dini pada remaja terutama tentang persiapan masa 1000 Hari Pertama Kehidupan juga dapat meningkatkan resiko melahirkan anak dengan gangguan pertumbuhan hingga terjadinya stunting. Tujuan kegiatan pengabdian masyarakat untuk meningkatkan perilaku pencegahan stunting pada remaja desa Taban, Kecematan Jambe, Kabupaten Tangerang. Metode yang digunakan adalah penyampaian materi dan pengisisan kuesioner terkait pencegahan stunting. Kegiatan pengabdian masyarakat ini dilaksanakan penyuluhan kesehatan terkait pencegahan stunting dengan media audiovisual dan non-audiovisual. Hasil kegiatan adanya komitmen kepada peserta untuk melakukan penyebaran informasi kepada remaja lain dan adanya perubahan perilaku remaja dari negatif menjadi positif terkait pencegahan stunting. Diharapkan dengan adanya peningkatan perilaku pada remaja maka dapat menekan angka kejadian stunting.
\end{abstract}

Kata kunci: audiovisual; non-audiovisual; promosi kesehatan; remaja; stunting

\section{ABSTRACT}

The quality of a teenager is one of the factors that can determine the incidence of stunting. The lack of providing correct information about preparing for stunting prevention from an early age in adolescents, especially about preparation for the first 1000 days of life can also increase the risk of giving birth to children with growth disorders and stunting. The purpose of community service activities is to improve stunting prevention behavior in adolescents in Taban village, Jambe district, Tangerang district. The method used is the delivery of materials and filling out a questionnaire related to stunting prevention. This community service activity is carried out by providing health education related to stunting prevention with audiovisual and non-audiovisual media. The results of the activity were a commitment to participants to disseminate information to other teenagers and a change in adolescent behavior from negative to positive related to stunting prevention. It is hoped that with an increase in behavior in adolescents, it can reduce the incidence of stunting.

Keywords: audiovisual; non-audiovisual; health promotion; teenager; stunting

\section{PENDAHULUAN}

Indonesia sedang menghadapi berbagai masalah terkait kesehatan, termasuk tingginya angka kejadian stunting. Permasalahan stunting penting untuk segera dilakukan tindakan pencegahan karena dapat berakibat pada menurunnya kualitas sumber daya khususnya di bidang kesehatan dan dapat berakibat pada peningkatan kasus kematian pada anak. Menurut WHO dalam (Saadah, 2020), stunting merupakan gangguan pertumbuhan pada anak yang disebabkan oleh asupan nutrisi yang buruk, infeksi berulang dan stimulasi psikososial yang tidak adekuat.
Kualitas suatu remaja merupakan salah satu faktor yang dapat menentukan angka kejadian stunting. Kurangnya pemberian informasi yang benar tentang memeperisapkan pencegahan stunting sejak dini pada remaja terutama tentang persiapan masa 1000 Hari Pertama Kehidupan juga dapat meningkatkan resiko melahirkan anak dengan gangguan pertumbuhan hingga terjadinya stunting. Status Indonesia masih berada di urutan keempat dunia dan urutan kedua di Asia Tenggara terkait kasus balita stunting.

Diketahui, jumlah kasus stunting di Indonesia pada tahun 2019 mencapai 27,67 
persen. Angka tersebut masih dinilai tinggi, mengingat $\mathrm{WHO}$ menargetkan angka stunting tidak boleh lebih dari $20 \%$. Adanya kejadian stunting dapat disebabkan oleh berbagai faktor. Diantara 5 juta kelahiran bayi setiap tahun, sebanyak 1,2 juta bayi lahir dengan kondisi stunting. Stunting itu adalah produk yang dihasilkan dari kehamilan. Bayi baru lahir yang mengalami stunting sebanyak $23 \%$. Sedangkan, bayi yang lahir secara normal kemudian menjadi stunting sebanyak 27,6\% (BKKBN, 2021). Sebanyak 15.318 balita di Kabupaten Tangerang, Banten terindentifikasi mengalami gangguan pertumbuhan atau stunting (Saaadatuddaraen, 2021).

Oleh karena itu, untuk meningkatkan perilaku positif terhadap pencegahan stunting pada remaja maka penting untuk dilakukan edukasi dan persiapan dalam bentuk kegiatan berupa promosi kesehatan terkait stunting yang dapat dilakukan sejak dini, khususnya untuk para remaja. Perilaku merupakan respon terhadap rangsangan dari luar. Menurut Peraturan Menteri Kesehatan No. 74 Tahun 2015 tentang upaya peningkatan dan pencegahan penyakit, merumuskan promosi kesehatan merupakan proses untuk memberdayakan masyarakat melalui kegiatan menginformasikan, mempengaruhi dan membantu masyarakat berperan aktif untuk mendukung perubahan perilaku dan lingkungan serta menjaga dan meningkatkan kesehatan yang optimal (Pakpahan, M., 2021).

Pemilihan media dalam penyampaian promosi kesehatan juga penting untuk diperhatikan. Media yang digunakan untuk memberikan promosi kesehatan antara lain media audiovisual, dimana dianggap lebih baik dan menarik, sebab mengandung kedua unsur, yaitu di dengar dan di lihat. Selain itu media promosi kesehatan lainnya adalah media nonaudiovisual. Salah satu media non-audiovisual yang sering digunakan adalah leaflet. Bentuk penyampaian informasi atau pesan-pesan kesehatan pada leaflet melalui lembaran yang dilipat. Isi informasi dapat berbentuk kalimat maupun gambar atau kombinasi.

Menurut penelitian (Jannah, N.M \& Endar, 2020), terdapat pengaruh pelaksaanaan pendidikan kesehatan melalui media leaflet dengan nilai $(p=0,000)$ dan pendidikan kesehatan melalui media audiovisual $(p=0,000)$. Hasil penelitian (Hartoyo, E. D., \& Bela, 2021), dari respoden terdapat 67 responden yang mengalami peningkatan pada nlai pre-test dengan posttest. Dapat disimpulkan ada pengaruh pendidikan kesehatan menggunakan leaflet tentang kebersihan personal hygiene genitalia eksternal pada saat menstruasi terhadap pengetahuan dan perilaku remaja di
Pondok Pesantren Al-Qur'an Insan Pratama dengan nilai $p<0,05$.

Berdasarkan penelitian (Jannah, A. F., \& Sofiana, 2019), menunjukkan bahwa penerapan edukasi dengan media audio visual dan modul efektif meningkatkan perilaku ibu tentang pemberian MP-ASI terhadap bayi usia 6-24 bulan, dibuktikan dengan semua responden memiliki tingkat perilaku dengan kategori baik dengan prosentase $100 \%$.

\section{METODE}

Pengabdian masyarakat dilakukan pada hari sabtu, 8 Mei 2021 di gedung majelis taklim Desa Taban, Kecamatan Jambe, Kabupaten Tangerang. Pelaksanaan pengabdian masyarakat menggunakan sasaran yaitu 20 remaja yang terbagi dalam dua kelompok. 10 remaja pada kelompok pemberian promosi kesehatan dengan media audiovisual dan 10 remaja dengan media nonaudiovisual.

Metode yang digunakan adalah pengisian kuesioner pre dan posttest serta penyampaian materi tentang pencegahan stunting menggunakan media audiovisual dan non-audiovisual. Narasumber berasal dari Dosen Keperawatan STIKes YATSI Tangerang. Setelah pemaparan materi, dilakukan sesi Tanya jawab dan diskusi.

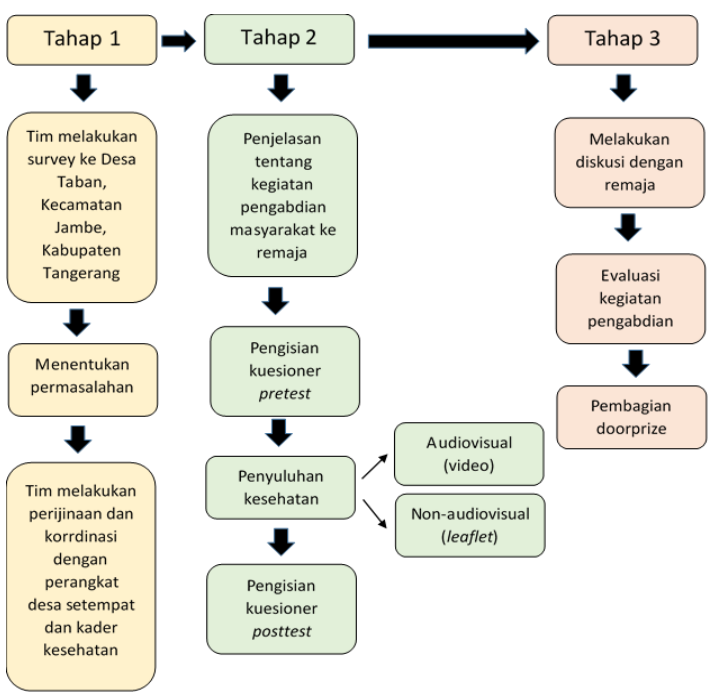

Gambar 1. Alur Pelaksanaan Pengabdian

Pelaksanaan kegiatan dilakukan dengan 3 tahapan, dimana tahapan pertama merupakan tahap persiapan. Pada tahap pertama, tim melakukan survey dan melakukan perijinan pada perangkat desa setempat, dalam tahap ini dilakukan juga pencarin permasalah yang dihadapi remaja setempat terkait stunting. Tahap kedua merupakan tahap pelaksanaan kegiatan, kegiatan dilakukan dengan pengisian 
kuesioner perilaku dan penyuluhan kesehatan dengan media audiovisual dan non-audiovisual tentang pencegahan stunting. Tahap terakhir adalah evaluai dan diskusi, masukan dan perbaikan lebih lanjut dapat dilakukan pada tahap ini. Evaluasi diberikan dengan mengumpulkan data yang diperoleh dari pengisian kuesioner.

\section{HASIL DAN PEMBAHASAN}

\section{Pengisian Kuesioner}

Kegiatan penyuluhan kesehatan dihadiri oleh 20 remaja dan beberapa kader serta perangkat desa terkait. Dilakukan pengukuran variabel perilaku dengan pengisian kuesioner. Kuesioner diisi sebelum dan sesudah dilakukan penyuluhan kesehatan.

Hasil dari pengukuran tingkat perilaku remaja pada kegiatan pengabdian masyarakat ditunjukkan dalam tabel 1 berikut ini:

Tabel 1. Distribusi Perilaku Remaja

\begin{tabular}{llccc}
\hline Variabel & \multicolumn{2}{c}{ AV } & \multicolumn{2}{c}{ Non } \\
& Pre & Post & Pre & Post \\
\hline Perilaku & & & & \\
- Positif & $3(30 \%)$ & $9(90 \%)$ & $1(10 \%)$ & $6(60 \%)$ \\
- Negatif & $7(70 \%)$ & $1(10 \%)$ & $9(90 \%)$ & $4(40 \%)$ \\
\hline
\end{tabular}

Hasil pengisian kuesioner menunjukkan bahwa ada peningkatan perilaku sebelum dan sesudah diberikan penyuluhan kesehatan menggunakan media audiovisual dan non-audiovisual. Sebelum diberikan penyuluhan rata-rata remaja memiliki perilaku yang negatif, sedangkan sesudah penyuluhan rata-rata remaja meiliki perilaku positif.

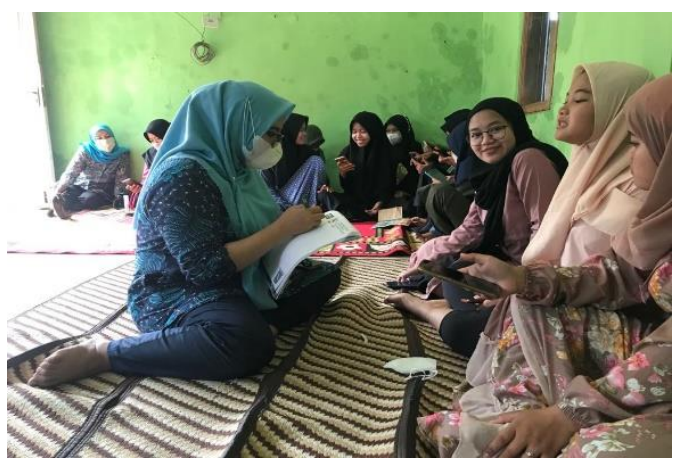

Gambar 1. Pengisian Kuesioner

\section{Penyuluhan Kesehatan}

Kegiatan penyuluhan kesehatan dilaksanakan menggunakan dua media, yaitu media audiovisual dan non-audiovisual. Materi yang disampaikan terkait dengan pencegahan stunting.penyuluhan dnegan media audiovisual dipaparkan dnegan pemutaran video berupa slide. Sedangkan, penyuluhan dengan media non-audiovisual dengan pembagian leaflet.

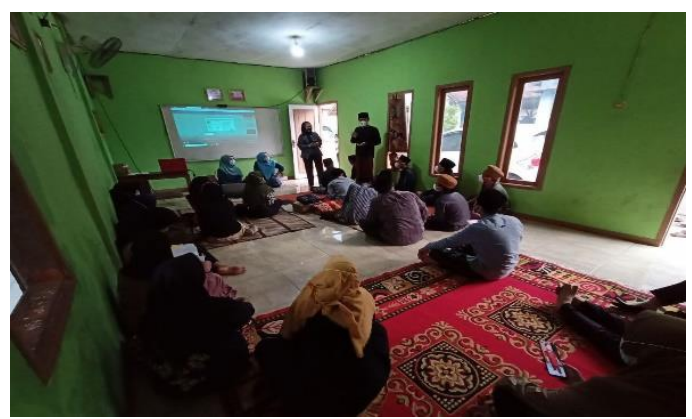

Gambar 2. Penyuluhan Kesehatan

\section{Evaluasi dan Diskusi}

Pembagian doorprize diberikan kepada seluruh peserta yang berpartisipasi pada kegiatan pengabdian masyarakat, doorprize juga diberikan kepada peserta yang mengjaukan pertanyaan pada sesi Tanya jawab. Doorprize diberikan agar peserta semangat dalam mengikuti kegiatan pengabdian dari awal sampai akhir kegiatan. Setelah itu, diakhir acara dilakukan evaluasi bersama terhadap hasil kegiatan pengabdian masyarakat.

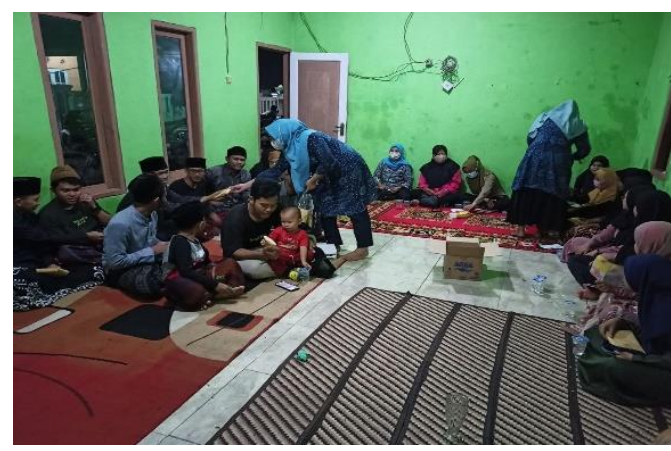

Gambar 3. Pembagian Doorprize

\section{SIMPULAN DAN SARAN}

Dari hasil kegiatan pengabdian masyarakat pada remaja di Desa Taban, Kecamatan Jambe, Kabupaten Tangerang dapat disimpulkan bahwa semakin meningkat perilaku peserta, peserta dapat memahami pencegahan stunting yang dapat dilakukan sejak dini. Oleh karena itu, dengan adanya kegiatan ini diharapkan dapat menekan angka kejaidan stunting di Desa Taban, Kecamatan Jambe, Kabupaten Tangerang. Disarankan agar kader kesehatan selalu memberikan edukasi kepada masyarakat terkait pencegahan stunting. 


\section{UCAPAN TERIMAKASIH}

Ucapan terimakasih kami ucapkan kepada perwakilan BBKBN Provinsi Banten dan STIKes YATSI yang telah memfasilitasi jalannya kegiatan pengabdian masyarakat. Masyarakat dan perangkat desa Taban yang memberikan ijin dan mendukung jalannya kegiatan.

\section{DAFTAR RUJUKAN}

BKKBN. (2021). Antisipasi Generasi Stunting Guna Mencapai Indonesia Emas 2045. https://www.bkkbn.go.id/detailpost/indone sia-cegah-stunting

Hartoyo, E. D., \& Bela, N. A. S. (2021). Pengaruh Media Leaflet Tentang Personal Hygiene Genitalia Pada Saat Menstruasi Terhadap the Influence of the Leaflet Media Towards Personal Hygiene Genitalia Menstruation of Adolescents. IKESMA: Jurnal IImu Kesehatan Masyarakat, 17, 1. https://doi.org/10.19184/ikesma.v17i1.20 402

Jannah, A. F., \& Sofiana, J. (2019). NoPenerapan Edukasi Dengan Media Audio Visual Dan Modul Terhadap Pengetahuan Dan Perilaku Ibu Tentang Pemberian MP-ASI Title. Jurnal Sekolah Tinggi IImu Kesehatan Muhammadiyah Gombong, 764-772.

Jannah, N.M \& Endar, T. (2020). Perbandingan Efektivitas Pendidikan Kesehatan dengan Media Leaflet dan Audio Visual dalam Meningkatkan Pengetahuan Remaja tentang Pemeriksaan Payudara Sendiri (SADARI). Jurnal Keperawatan Terpadu (Integrated Nursing Juournal), 2(2), 80-90.

Pakpahan, M., dkk. (2021). Promosi Kesehatan dan Perilaku Kesehatan. Yayasan Kita Menulis.

Saaadatuddaraen. (2021). Belasan Ribu Balita Kabupaten Tangerang Alami Stunting. https://rri.co.id/daerah/1033388/belasanribu-balita-kabupaten-tangerang-alamistunting\#

Saadah, N. (2020). Modul Deteksi Dini Pencegahan dan Penanganan Stunting. Scopindo Media Pustaka. 